\title{
Milk Tea Purchasing Behaviour among the Youth: A Study in Sibu Town
}

\author{
Kiew Jiet Ping ${ }^{1 *}$, Evelyn Toh Ting Ling $^{2}, \&$ Michelle Eu Hui Sing ${ }^{2}$ \\ ${ }^{1}$ Department of Accountancy, School of Business and Management \\ ${ }^{2}$ Department of Business Administration, School of Business and Management \\ University College of Technology Sarawak \\ *Corresponding author: Kiew.jiet.ping@ucts.edu.my
}

\begin{abstract}
This article aims to identify the factors affecting milk tea purchasing behaviour in Sibu town. Starting from year 2019, milk tea shops started to sprout up like mushrooms after rain. Of the 288000 Sibu population, youth population recorded 40 percent. Thus, the competition of milk tea is high in Sibu town. As such, it is vital to study factors influencing the purchasing behaviour in turn to develop a suitable marketing mix for business sustainability. In this study, targeted population is youth population, who aged from 15 to 30 years old. To collect the primary data, quantitative method is used by developing survey questionnaires through Google Form. Approximately, 344 valid responses were collected and analysed using SPSS statistical tool. The result found that personal, social, and psychological factors were significantly related to milk tea purchasing behaviour among the youth in Sibu town. Unfortunately, the finding also indicated that cultural factor has no significant relationship on consumer buying behaviour of milk tea in Sibu. The results help the potential and existing milk tea investors to identify the factors affecting milk tea purchasing behaviour. This study recommends the milk tea potential and existing investors to take personal, social, and psychological factors into consideration while developing and implementing business strategy.
\end{abstract}

Keywords: Consumer purchasing behaviour, personal, culture, psychological, social

\section{Introduction}

Malaysia achieves 250 percent growth in bubble tea and the average milk tea consumption is three cups per person monthly (Yim \& Lee, 2019). Milk tea drinks are designed to appeal young customers as a way for brands to be part of 'viral food' trends (The Asean Post team, 2019). Thus, the young generation has created a milk tea trend since this kind of tea drink had successfully become their interests (Foong, 2019). The demand of milk tea will eventually cool off and once the popularity of milk tea loses, the market will adjust the supply to demand and only the reputatable businesses can sustain longer (Pillai, 2019).

In 2019, bubble tea shops started to sprout like mushrooms after rain in Malaysia. There are numerous franchised milk tea shops which can be found in Sibu Town square and commercial center near Jalan Dr. Wong Soon Kai. Approximately, youth population is recorded at 40 percent out of 288000 population in Sibu town. It is therefore assured that the competition of milk tea is considered higher in Sibu town. Therefore, to develop a strategic marketing mix, it is vital to study factors influencing the purchasing behaviour among the youths. 


\section{Literature Review}

\section{Consumer purchasing behaviour}

Consumer purchasing behaviour is defined as the sum total of consumer's attitudes, preferences, intentions, and decision-making process that possess by consumers in the marketplace (Grimsley, 2015). It is a process of choosing, purchasing, utilising, and disposing of products or services by an individual to fulfil customer's needs and wants (Solomon, 1995). Consumer purchasing behaviour involves a series of activities, such as consumer buying decision and it may create level of satisfaction among the customers (Kotler \& Armstrong, 2014).

\section{Personal Factors}

As noted in literature reviewing, age and life cycle, economic situation, and lifestyle are contribute to consumer's buying behaviour (Lautiainen, 2015). Age is the significant determinant in marketing strategies because it creates a difference among individual's purchasing pattern (Rehman, Yusoff, Zabri, \& Ismail, 2017). An individual's age affect the changes of people's lifestyle, needs, and personal values (Pratap, 2019). Consumers on the upper age level will more likely to avoid purchasing those with high contain sugar and cholesterol to minimize the risk of health problems (Rehman et al., 2017). For the individual's life circle stage, the products of chocolates, sweets, and toys are meant for children (Pratap, 2019). The young generation is preferred to spend lavishly on the items of beer, parties, clubs, clothes, and so on. Evidently, young generation is unable to purchase high-involvement products, such as property, house, furniture, and so on (Juneja 2015). Additionally, individuals who have the family are preferred to buy something which is beneficial for his family and future secure (Juneja, 2015).

Besides, economic factors may also influence consumer purchasing decisions and behaviour (Pratap, 2019). People with low-income level probably will tend to purchase the needed products and avoid to purchase luxury products. In contrast, people with high-income level are intended to purchase branded product and they have strong purchasing power (Lautiainen, 2015).

The lifestyle of consumers such as, interest, choices, preferences, values, and opinions are significantly affected consumer buying behaviour (Rehman et al., 2017). An individual who intends to have a healthy lifestyle, he or she may likely to purchase organic foods instead of consuming junk foods or soft drinks (Lautiainen, 2015).

\section{Cultural Factors}

Despite personal factors, cultural factors which make up of a buyer's culture and sub-culture may lead to an individual's buying behaviour (Shah, 2010). As stated, culture is the most fundamental determinant of a consumer's want and behaviour (Ramya \& Ali, 2016). It creates a direct impact on how we live and what to consume (Durmaz \& Jablonski, 2012). In other words, individuals may determine their behaviour and pattern of consumption thus influence the decision making via multi-cultural society.

The marketers explored the forces of culture to develop marketing strategies that fit different kinds of culture group's preferences to boost the sales and profits. For example, the Coca-Cola Company which produces Fanta adopted the culture taste preferences strategy by 
bringing the flavour to fit the culture of a certain market. The taste for Fanta in Japan more like flowers, peach flavoured in Botswana, and tastes of passion fruit in France (Hyatt, 2017).

Culture itself is consisted of sub-cultures that related to specific identification of an individual. Sub-culture is referred to a set of beliefs share within a sub-group of the main culture (Ramya \& Ali, 2016). It consists of religion, racial, or a group of people who share the geographical location, and these in turn will influence buying behaviour toward a particular product (Yakup \& Jablonski, 2012). As stated, sub-cultures can be categorised into religious groups, racial groups, and geographical areas. Religious groups such as, Muslims, Catholics, and Christian are eating beef, however, it is considered as a sin for Hindus. Racial is categorised as Chinese, Melayu, Iban, and Hindu. All these ethnicity are with difference references and attitude and behaviour. Lastly, geographical areas are divided into Deep South, California, and New England are distinct subcultures with characteristic lifestyles (Durmaz, 2014).

\section{Social Factors}

Social factors are the effect of people or groups influencing one's buying behaviour (Shah, 2010). These social factors can include reference groups, family, role, and status. Social factors such as reference groups, family, social roles and statues will influence the individual as a consumer (Cetina, Munthiu, \& Radulescu, 2012). Human beings are social animals. People always stay together to talk and discuss various issues, topic to get better solutions, ideas, opinions, feelings and thus produce an outcome or conclusion (Juneja, 2015). Social factors such as reference groups, family, role, and status will control consumer buying behaviour, the act whether to buy specific products or services.

A reference group is a person or group of people who significantly influence an individual's behaviour (Al-Azzam, 2014). Consumer buying behaviour was influenced when consumer listening to the opinions, feedbacks, knowledge, experiences of reference groups (Mirzaei \& Ruzdar, 2010). Reference groups are generally separate into two types that are primary groups and secondary groups (Juneja, 2015).

Primary groups refer to the reference group that has direct interaction with the consumers (Mirzaei \& Ruzdar, 2010). Primary groups can be consists of family, friends, relatives, and co-workers. Secondary groups refer to the reference group which has no direct interaction with the consumer but somehow changes consumer's buying behaviour. Secondary reference groups considered as more professional and formal groups such as models, artists, religious associations, and political parties.

Impacts of traditional attitudes, interests, and incentives belong to a family will not only as evidence in the development period but also extend and pass to their next generation (Durmaz \& Jablonski, 2012). The influences of parents and individual's upbringing have a strong effect on buying habits as well as buying behaviour. For example, an individual who come from a vegetarian family would not consume meat even though it produces nutritional value (Gajjar, 2013).

A role can be said as a series of activities that a person expects to perform and each role carries a person's status (Ramya \& Ali, 2016). The roles and status that belong to a person will influence his or her buying behaviour (Nguyen \& Gizaw, 2014). When a person accepts a role, the role will affect the person to act in a special way (Mirzaei \& Ruzdar, 2010). Each individual 
plays an important role in society depends on which group he or she belongs to while at the same time, the buying tendency and buying behaviour depend heavily depends on the roles he or she possesses in society. (Juneja, 2015).

\section{Psychological Factors}

Psychological factors are related to motivation, perception, learning, beliefs, and attitudes will have a certain impact on the buyer's choices (Lautiainen, 2015). As noted, motivation and perception enacted as determinants of consumer buying decision (Ramya \& Ali, 2016). An individual customer has different kinds of needs. These needs can be physiological needs, social needs, and biological needs that used to measure customer desire. Individual's need is aroused when a motive is existed (Lautiainen, 2015). Motivation is a need that drives a person to seek satisfaction and fulfilment. Thus, a need becomes motivation when it has more power to direct a person to seek satisfaction.

"Maslow's Hierarchy of needs" explains the link between the motivations and needs (Cherry, 2019). When a basic need has been fulfilled and people tend to focus on the next most important need (Lautiainen, 2015). Maslow's needs are comprised of physiological needs (e.g., food, water, sleep, and warmth), safety needs (e.g., safety, financial security), social needs (e.g., feeling sense of love), esteem needs (e.g., participation in professional activities and academic accomplishment), and lastly self-Actualization needs (e.g., achieve their full potential as human beings).

Perception is the process of selecting, organizing, and interpreting information in a way to produce a meaningful experience of the world. Perception is how human perceive and position things in their mind (Shah, 2010). Individuals with the same needs might not purchase similar products due to differences in perception toward the products and brands (Juneja, 2015). Consumers have the possibility of forming different perceptions of stimuli due to the threestage perceptual process (Yakup \& Jablonsk, 2012), namely selective attention, selective distortion, and selective retention. Selective attention is the stage where the consumers focus on the stimuli which related to current needs. It is referred to how the consumers interpret the information in a way that will support what the customers already believe. Selective retention is the stage where consumers remember the information that supported what they believed.

Learning will change the individual behaviour who acquired information and experience from learning. For example, a person may obtain a lesson based on their past experience (positive or negative) with certain product. Similarly, if a person has a good experience with the product, he or she will rebuy it (Rani, 2014). Furthermore, people can learn and gain knowledge via observation. They receive feedback from others, whether the product or brand is good or not. Hence, when people make an observation, it can be said as they are learning and it will affect their behaviour as a consumer (Lautiainen, 2015).

Belief is defined as "descriptive thought that a person holds about something." It is based on a person's real knowledge, faith, or opinion. Attitude means a person's feelings, emotions, actions show towards somethings or ideas (Yakup \& Jablonsk, 2012). Consumers always possess different beliefs and attitudes towards products and services which will make up the brand image and affect consumer buying behaviour (Shah, 2010). If a consumer's belief toward a product is favourable, it would produce a positive impact on consumer buying behaviour (Williams, 2014). 


\section{Conceptual Framework}

The researcher has developed the framework for this study. The conceptual framework includes four independent variables, namely personal factors, cultural factors, social factors, and psychological factors. The dependent variable is milk tea purchasing behaviour among the youth.

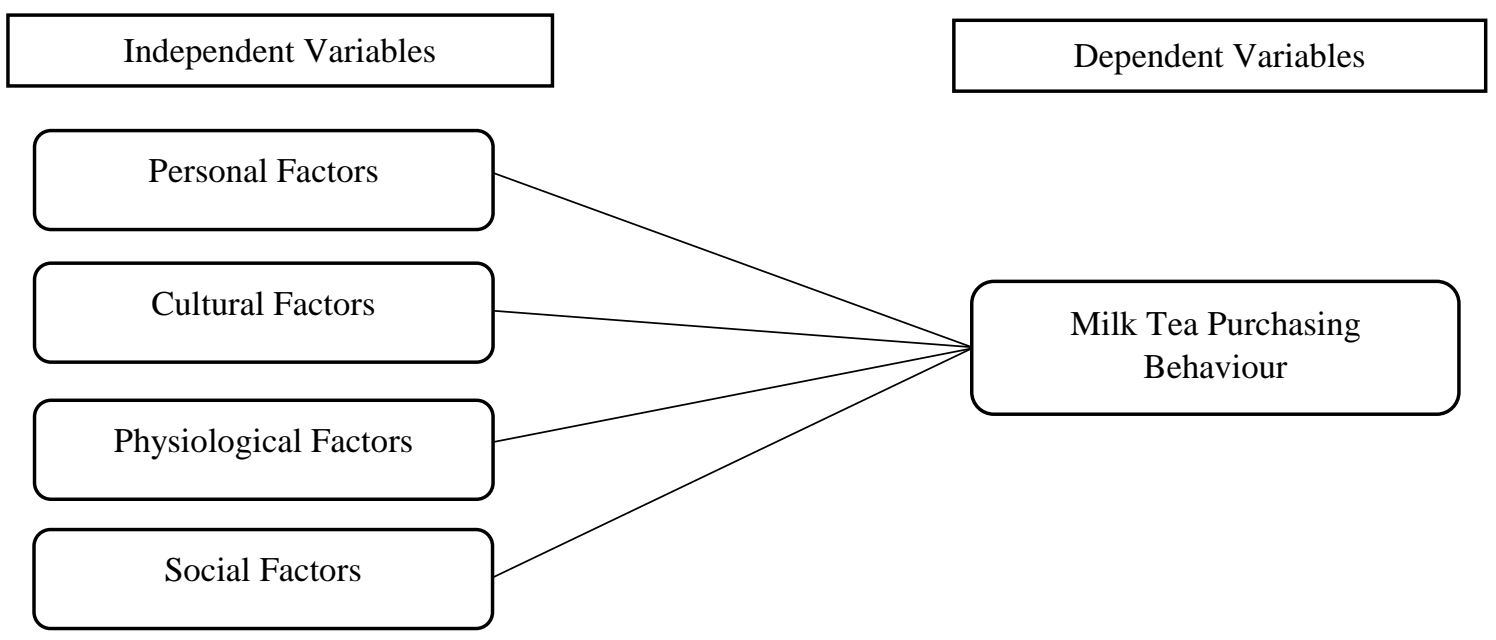

Figure 1: Conceptual Framework

Source: Authors

As shown in stimulus-response model (Figure 2), marketing and other stimuli enter into "black box" and produce buyer's response which is the buyer's decision. Marketers want to understand how the stimuli transformed into response in the black box. The black box has two parts which is the consumer's characteristics and decision process. Consumer's characteristics affect how the consumers react to the stimuli. Decision process affects consumer behaviour. Marketing stimuli consist of 4Ps which are product, price, place and promotion. While other stimuli consist economic, technological, political and cultural. Consumer's characteristics are affected by cultural, social, personal, and psychological. All these factors will be chosen in this study. Figure 3 demonstrated the details of factors Influencing Consumer Behaviour. 


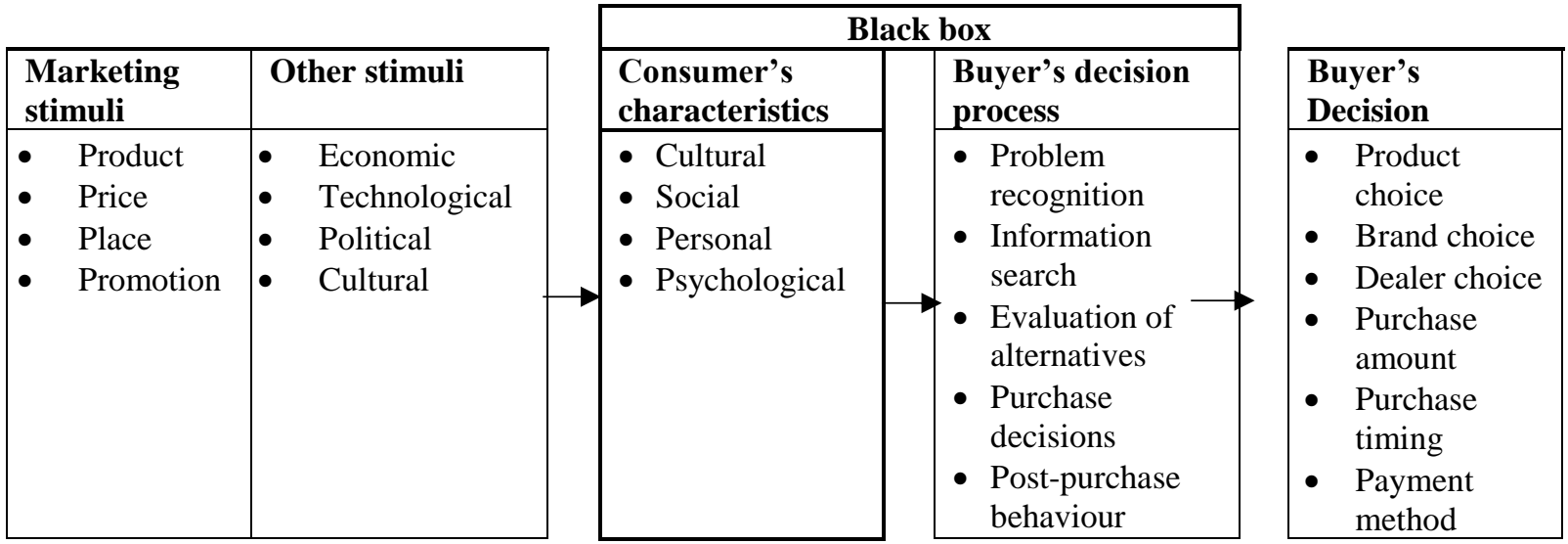

Figure 2: Model of Consumer Behaviour

Source: Kotler \& Keller (2016).

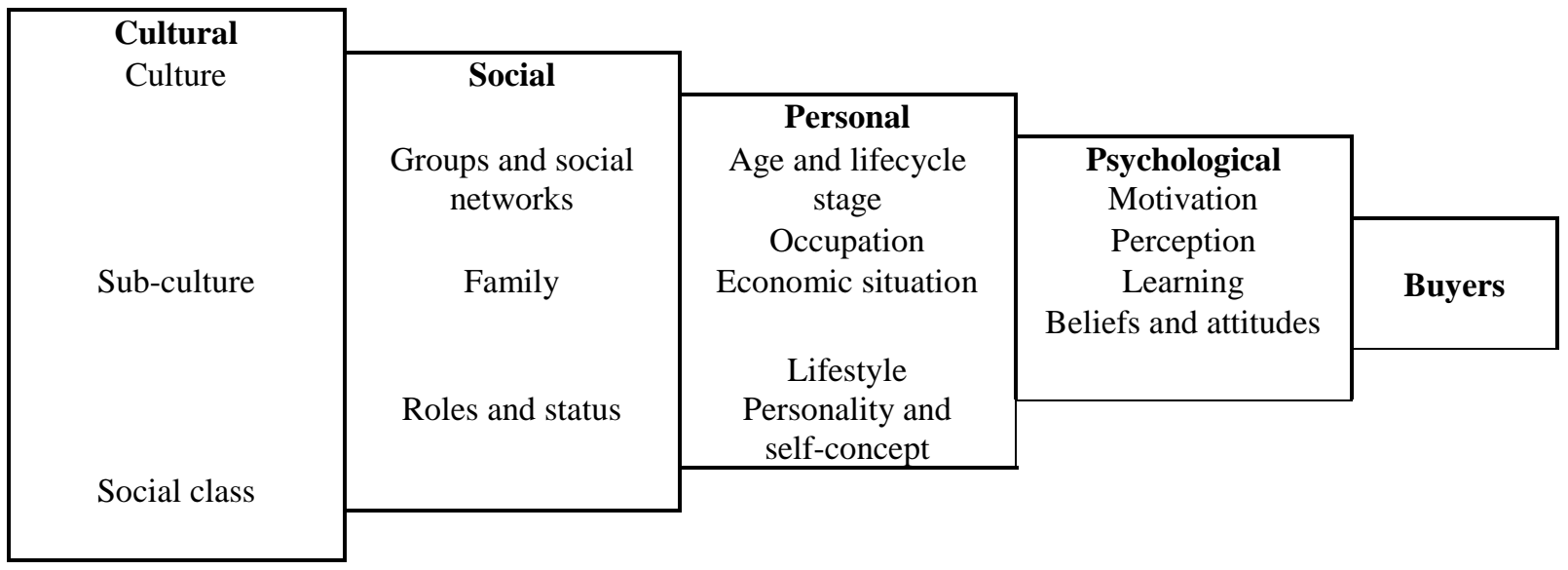

Figure 3: Factors Influencing Consumer Behavior

Source: Kotler \& Armstrong (2016)

\section{Hypotheses Development}

In this section, the researcher hypothesizes that the formulated hypotheses have a direct relationship between independent variables and dependent variables as highlighted in the proposed conceptual framework. The proposed hypotheses are shown as below:

$\mathrm{H} 1$ : Personal factors are significantly related to milk tea purchasing behaviour among the youth in Sibu town.

$\mathrm{H} 2$ : Cultural factors are significantly related to milk tea purchasing behaviour among the youth in Sibu town.

H3: Social factors are significantly related to milk tea purchasing behaviour among the youth in Sibu town.

H4: Psychological factors are significantly related to milk tea purchasing behaviour among the youth in Sibu town. 


\section{Research Methodology}

Quantitative research is used to determine the factors influencing milk tea purchasing behaviour among the youth in Sibu town. It is used to quantify the problem by the way of generating numerical data into usable statistics (DeFranzo, 2011). The quantitative research is an appropriated approach that helps the researcher in measuring and testing the hypotheses through a series of numbers and data (Sekaran \& Bougie, 2009). The quantitative data will be collected by developing survey questionnaires through Google Form. A self-administered survey was used to obtain the primary data. The questionnaire was written in English because these representative were expected to be proficient in English.

In this study, the targeted population is youth. In Malaysia, youth is defined as those youngster who are from 15 to 30 years old in accordance to the Youth Societies and Youth Development Act (Amendment) 2019 (Act668) (New Straits Times, 2019). In fact, the milk tea drinks are designed to appeal to young consumers and they are the group that get the milk tea become a part of trends (The ASEAN Post Team, 2019). Evidently, Milk tea is highly dependent on young consumers and skews strongly toward consumers under the age of 30 in the UK (Byrne, 2019). There is a high demand of milk tea among young population that given high potential for milk tea market expansion (Sangwai \& Deshmukh, 2020). Non-probability sampling method (purposive sampling) is used to conduct the research. An appropriate sample size for the research is in the range of 30-500 (Roscoe 1975). The Google Form invitation has been sent out and 344 feedbacks were collected. The main statistical tool to analysis the primary data is Statistical Analysis in Social Science (SPSS).

\section{Findings}

There are 344 respondents participated in this survey. The researcher utilised descriptive statistics to obtain the general information of the respondents. A complete demographic profile of the respondents is presented in Table 1.

Table 1 Demographic Information of Respondents

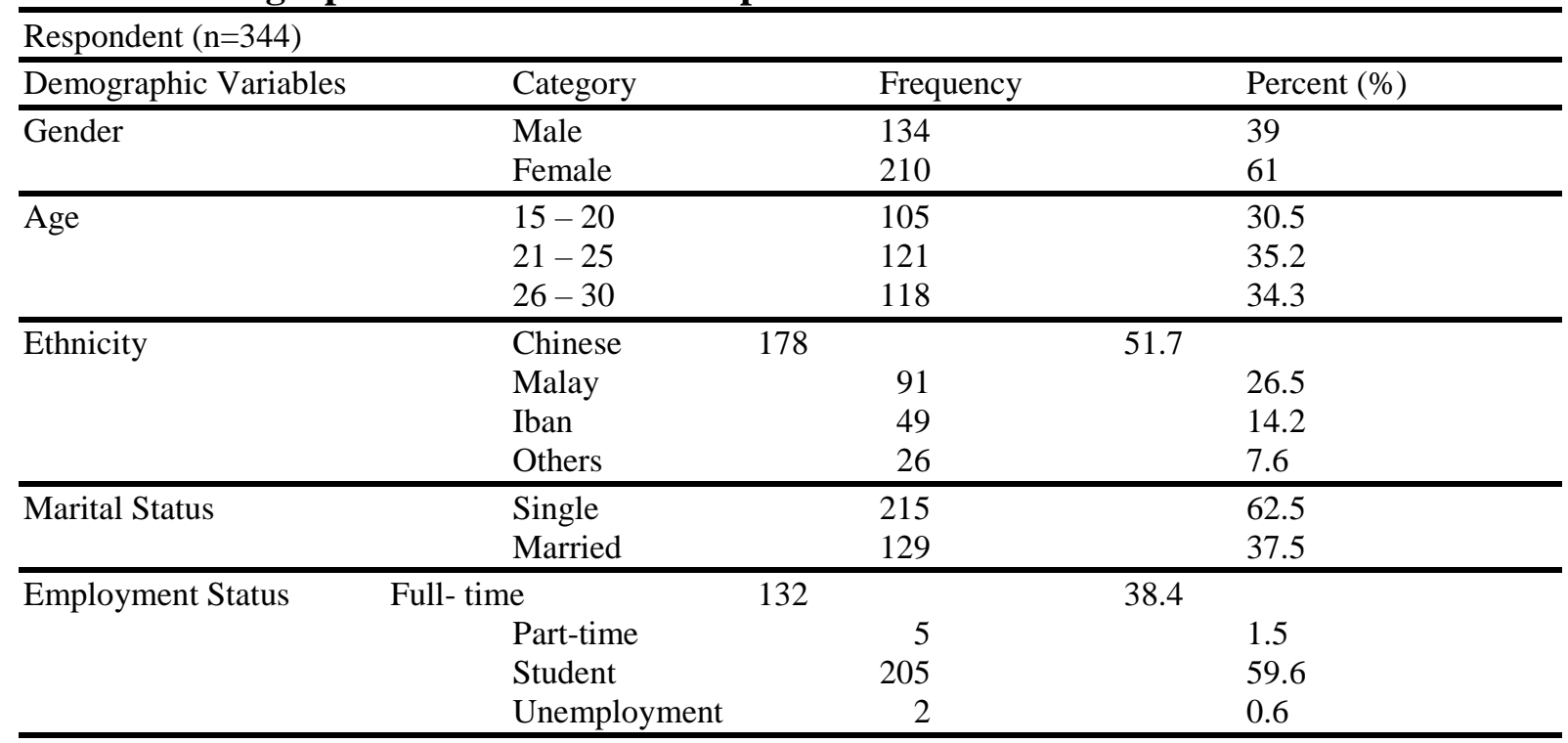


Borneo Journal of Social Sciences \& Humanities

DOI: https://doi.org/10.35370/bjssh.2021.3.1-05

e-ISSN: 2682-8235

(C) 2018, UCTS Publisher.

\begin{tabular}{|c|c|c|c|}
\hline Submitted: 30 April 2021 & \multicolumn{2}{|c|}{ Accepted: 23 June 2021} & Published: 30 June 2021 \\
\hline \multirow[t]{5}{*}{ Income Status } & Less than RM1,000 & 24 & 7.0 \\
\hline & RM1,001 - RM2,500 & 47 & 13.7 \\
\hline & RM2,501 - RM4,000 & 78 & 22.7 \\
\hline & RM4,001 - RM5,500 & 12 & 3.5 \\
\hline & No income/ Allowance & 183 & 53.2 \\
\hline \multirow[t]{5}{*}{ Highest Education } & University Degree & 119 & 34.6 \\
\hline & Diploma & 80 & 23.3 \\
\hline & Foundation & 67 & 19.5 \\
\hline & Secondary School & 58 & 16.9 \\
\hline & Others & 8 & 2.2 \\
\hline
\end{tabular}

Source: Authors

Table 2 General Behaviour of Milk Tea Consumption

\begin{tabular}{|c|c|c|c|}
\hline General behaviour & Category & Frequency & Percent $(\%)$ \\
\hline \multirow[t]{2}{*}{ Milk tea lover } & Yes & 257 & 74.7 \\
\hline & No & 87 & 25.3 \\
\hline \multirow[t]{4}{*}{ Frequency of purchase } & 1 - 2 per week & 110 & 32.0 \\
\hline & 3 - 5 per week & 7 & 2.0 \\
\hline & Every day & 2 & 0.6 \\
\hline & Rarely & 225 & 65.4 \\
\hline \multirow[t]{4}{*}{ Money spent per cup } & Below RM7 & 30 & 8.7 \\
\hline & Below RM10 & 113 & 32.8 \\
\hline & Below RM15 & 188 & 54.7 \\
\hline & Below RM20 & 13 & 3.8 \\
\hline \multirow[t]{9}{*}{ Favour Milk Tea Brand } & Daboba & 29 & 8.4 \\
\hline & Easy Go Easy Drink & 18 & 5.2 \\
\hline & HICCA & 140 & 40.7 \\
\hline & Macau Imperial tea & 48 & 14.0 \\
\hline & Regiustea & 2 & 0.6 \\
\hline & Share Tea & 37 & 10.8 \\
\hline & Truedan & & 8.7 \\
\hline & Wikitea & 15 & 4.4 \\
\hline & Xin Fu Tang & 25 & 7.3 \\
\hline
\end{tabular}

Source: Authors

Table 3 Mean and Standard Deviation of Variables

\begin{tabular}{lcc}
\hline Variables & Mean & Std. Deviation \\
\hline Personal Factors & 4.0291 & .88962 \\
Cultural Factors & 2.2049 & .82958 \\
Social Factors & 4.8234 & 1.18523 \\
Psychological Factors & 3.0240 & 1.05738 \\
Consumer Buying Behaviour & 3.4128 & .43493
\end{tabular}

The summary of the mean and standard deviation of the major variables statistics in Table 3 were analysed based on 344 responses. The factor that has get the lowest mean is cultural factors, which is 2.2049. And, the social factors owned the highest mean, which is 
4.8234. It also indicates that most of respondents agree that social factor will influence their buying behaviour of milk tea. However, as social factors got a highest standard deviation which is 1.18523 , and psychological factors 1.05738 of standard deviation, demonstrating that respondents had different opinions on the social factors and psychological factors.

Table 4 Coefficients and Hypothesis Testing

\begin{tabular}{|c|c|c|c|c|c|c|}
\hline & \multirow[b]{3}{*}{ Model } & \multicolumn{5}{|c|}{ Standardized } \\
\hline & & \multicolumn{2}{|c|}{ Unstandardized Coefficients } & \multirow{2}{*}{$\frac{\text { Coefficients }}{\text { Beta }}$} & \multirow[b]{2}{*}{$\mathrm{t}$} & \multirow[b]{2}{*}{ Sig. } \\
\hline & & $\mathrm{B}$ & Std. Error & & & \\
\hline \multirow[t]{5}{*}{1} & (Constant) & 4.071 & .115 & & 35.370 & .000 \\
\hline & Personal factors & .056 & .035 & .114 & 3.607 & .021 \\
\hline & Cultural factors & .109 & .026 & .207 & 1.160 & .159 \\
\hline & Social factors & .096 & .031 & .261 & 4.058 & .002 \\
\hline & Psychological factors & .042 & .037 & .103 & 2.157 & .048 \\
\hline
\end{tabular}

As presented in Table 4, there are three independent variables have a significant relationship with dependent variable. The personal factor, social factor, and psychological factor have a significant relationship toward consumer buying behavior as their P-value shows $0.021,0.002$, and 0.048 respectively. Unofortunately, the study found that cultural factor were not supported, as its P-value shows 0.159 . 
Borneo Journal of Social Sciences \& Humanities

DOI: https://doi.org/10.35370/bissh.2021.3.1-05

Table 5 Pearson's Correlations Analysis

\begin{tabular}{|c|c|c|c|c|c|c|}
\hline & & $\begin{array}{c}\text { Personal } \\
\text { factors }\end{array}$ & $\begin{array}{l}\text { Cultural } \\
\text { factors }\end{array}$ & $\begin{array}{l}\text { Social } \\
\text { factors }\end{array}$ & $\begin{array}{l}\text { Psychological } \\
\text { factors }\end{array}$ & $\begin{array}{l}\text { Consumer } \\
\text { buying } \\
\text { behaviour }\end{array}$ \\
\hline \multirow[t]{3}{*}{ Personal factors } & $\begin{array}{l}\text { Pearson } \\
\text { Correlation }\end{array}$ & 1 & $.226^{* *}$ & $.666^{* *}$ & $.696^{* *}$ & $.693^{* *}$ \\
\hline & Sig. (2-tailed) & & .000 & .000 & .000 & .000 \\
\hline & $\mathrm{N}$ & 344 & 344 & 344 & 344 & 344 \\
\hline \multirow[t]{3}{*}{ Cultural factors } & $\begin{array}{l}\text { Pearson } \\
\text { Correlation }\end{array}$ & $.226^{* *}$ & 1 & $.132^{*}$ & $.110^{*}$ & .036 \\
\hline & Sig. (2-tailed) & .000 & & .014 & .042 & .012 \\
\hline & $\mathrm{N}$ & 344 & 344 & 344 & 344 & 344 \\
\hline \multirow[t]{3}{*}{ Social factors } & $\begin{array}{l}\text { Pearson } \\
\text { Correlation }\end{array}$ & $.666^{* *}$ & $.132^{*}$ & 1 & $.811^{* *}$ & $.712^{* *}$ \\
\hline & Sig. (2-tailed) & .000 & .014 & & .000 & .000 \\
\hline & $\mathrm{N}$ & 344 & 344 & 344 & 344 & 344 \\
\hline \multirow[t]{3}{*}{ Psychological factors } & $\begin{array}{l}\text { Pearson } \\
\text { Correlation }\end{array}$ & $.696^{* *}$ & $.110^{*}$ & $.811^{* *}$ & 1 & $.671^{* *}$ \\
\hline & Sig. (2-tailed) & .000 & .042 & .000 & & .000 \\
\hline & $\mathrm{N}$ & 344 & 344 & 344 & 344 & 344 \\
\hline \multirow[t]{3}{*}{$\begin{array}{l}\text { Consumer } \\
\text { behaviour }\end{array}$} & $\begin{array}{l}\text { Pearson } \\
\text { Correlation }\end{array}$ & $.693^{* *}$ & $.036^{*}$ & $.712^{* *}$ & $.671^{* *}$ & 1 \\
\hline & Sig. (2-tailed) & .000 & .012 & .000 & .000 & \\
\hline & $\mathrm{N}$ & 344 & 344 & 344 & 344 & 344 \\
\hline
\end{tabular}

According to person's Correlations analysis (Table 5), the relationship between personal factors and consumer buying behaviour has a R-value of 0.693 , which is indicate a positive and a high degree of relationship as the value has above R-value of 0.5. Besides, the cultural factors with consumer buying behaviour has a very weak linear relationship as its R-value shows 0.036 , it can also indicates that there is no correlation between cultural factor with consumer buying behaviour because its R-value is very near to 0 . By the way, social factors with consumer buying behaviour have a very strong degree of linear relationship since their p-value is 0.712 , which is also the highest score of R-value among the four factors. Lastly, the R-value of psychological factors with consumer buying is showed as 0.671 , which is also above the acceptable R-value of 0.5 , and it is considered as high correlation. Thus, it means that there is a linear relationship between psychological factors with consumer buying behaviour.

\section{Discussion}

The reseracher found that personal, social, and psychological factors were led to milk tea buying behaviour among the youths. The findings of this study is consistent with the study of Gbadamosi (2019) that personal factors were influence consumer buying behaviour. Pratap (2019) stated that when human is growing and an increasing of age were therefore to influence their buying decisions. When consumer is young, he or she is preferred to purchase the products which is considered freshness for them and explore the new things (Juneja, 2015). Pratap (2019) also mentioned that personal factor such as, income level may influence the buying behaviour. Similarly, Lautianen (2015) also discovered that the income level will affect the consumer's buying behaviour and thus influence their purchasing decision. Shah (2010) revealed that, 
higher income level may drive individual consumer to purchase more quantity and expensive products. However, for the lower the income consumers, he or she are alert on their spending.

In this research, social factor is significantly contribute to milk tea buying behaviour among the youths. The finding is further supported by Al-Azzam (2014), Shah (2010), and Mirzaei and Ruzdar (2010). They indicated that social factors are significant determinants to consumer behaviour. Besides, in family life cycle, an individual's attitudes, beliefs, and interests could pass to the next generation. If the parents hold a negative attitude towards an products, or pose a beliefs that a products may not be good for their children, they will demotivate their children to purchase it (Durmaz \& Jablonski, 2012). Moreover, secondary reference group has shown negative interaction with consumer, it controls consumer buying behaviour especially the artists and youtuber (Wilson, 2019).

Despite personal and social factors, the results also presented that psychological is significantly lead to consumer buying behavior. As noted in Theory of Consumer Behaviour, psychological factor such as, motivation, perception, beliefs and attitudes will influence consumer buying behaviour towards a particular products (Kotler \& Armstrong (2014). Motivation is the internal state that drive consumer to purchase, it is used to fulfill the desire needs and wants (Wilson 2019, Lautiainen 2015, \& Shah 2010). According to Abraham Maslow's Hierarchy of needs, our actions are motivated to achieve certain things, and Abraham Maslow stated that people first to satisfy the basid need then proceeding up the ladder. When customers possed the basic needs, they are motivated to obtain the next important and desire needs (Lautianen 2015).

Unfortunately, this research study found that cultural factor has no significant relationship towards consumer buying behaviour. Durmaz (2014) exposed that the sub-culture which are religious and racial will influence individual's behaviour as a consumer. It is because different consumer will have different religious and race, thus each religious and race has owned different culture that will influence their buying behaviour.

Today's beverage industry has a rapid expansion and especially coffee and tea has become a culture and popularity among Malaysians (CodeBlue, 2019). At the same time, beverage industry has performed well to offer their drinks that make it as localization thus everyone can enjoy tea drinks no matter what kind of religios, race, rituals and so on. Thus, milk tea has been fit into the Malaysian culture due to largely built with Malaysian's cohesion and passion on it, therefore generally milk tea has become a part of routine among Malaysians. In Malaysia, probably there are full with milk tea shops and there are every one in three people hold a cup of milk tea when walk around the shopping malls (Wong, 2018). The statistic that Malaysia consume three cups of milk tea per person per month (The ASEAN Post, 2019). According to the findings, milk tea drink has become a culture of Malaysia where we can see that all ethnic groups enjoy the milk tea regularly, just like the teh tarik was bring by Indian Muslim immigrant to Malaysia and nowadyas we can see all ethnic groups are enjoy of drinking it (Wong, 2018).

The international marketers in beverage industry has explored the forces of culture and develop marketing strategies that fit different kinds of culture group so all of ethnic groups can purchase it. For example, Coca-Cola Company has adopted the culture of Japan by offering the Fanta in Japan that taste like flower blossoms, peach flavour in Botswana, and tastes of passion fruit in France (Hyatt, 2017). Besides, based on the researcher's finding as well as selfpurchasing experience, there are milk tea outlets in Sibu adopt cultural localization strategies by offering the new milk tea drinks that aim to fit the culture of all Sibu people such as Milo bubble tea. Moreover, Malaysia government has said that if the milk tea is produced with 
ingredients that have been certified as halal, Muslims can also consume the milk tea that has no halal certificates (CodeBlue, 2019). Therefore, the researcher can conclude that cultural factor has become insignificant towards consumer buying behaviour of milk tea as milk tea business has localized their products that makes people with different culture will not be influenced to purchase it.

\section{Conclusion}

The findings steer us to draw conclusions that there is no either positive or significant relationship between cultural factor with consumer buying behaviour of milk tea in Sibu. And, it is proven that the consumer's personal factor, social factor, and psychological factor have a positive and significant relationship towards milk tea buying behaviour among the youths. The findings of this study may contribute to the investors of milk tea retailing store. The beverage industry players should concern the determinants of consumer's personal, social, and psychological factor in order design a strategy promotional mix. Besides, the results of this study can be used as fundamental guidance for the existing beverage owners and future entrepreneurs who are intended to venture in beverage industry in Sibu.

\section{Reference}

Abimbola, A. (2021). 5 Steps in the consumer decision-making process. Retrieved on 2 December 2020. Retrieved from https://mauconline.net/consumer-decision-makingprocess/

Akpan. \& John, S. (2016). The influence of cultural factors on consumer buying behaviour (A case study of Pork). European Centre for Research Training and Development UK, $4(6), 44-57$.

Al-Azzam, A. M. (2014). Evaluating effect of social factors affecting consumer behavior in purchasing home furnishing products In Jordan. European Centre for Research Training and Development UK, 2(7), 80-94.

Byrne, K. (2019). The case for Boba. Retrieved on 9 September 2020. Retrieved from: https://www.socialstandards.com/blog/boba-bubble-tea-consumer-trends

Cetina, I., Munthiu, M. C., \& Radulescu, V. (2012). Psychological and social factors that influence online consumer behavior. SciVerse ScienceDirect, 62, 184-188.

Cherry, K. (2019). The 5 levels of Maslow's Hierarchy of Needs. Retrieved on 3 December 2020. Retrieved from https://www.verywellmind.com/what-is-maslows-hierarchy-ofneeds-4136760

CodeBlue. (2019). Muslims can drink bubble tea not certified halal, government says. Retrieved on 3 December 2020. Retrieved from https://codeblue.galencentre.org/2019/12/18/muslims-can-drink-bubble-tea-notcertified-halal-government-says/

Crew, T. (2015). The history of tea. Retrieved on 3 December 2020. Retrieved from https://ttr.com.my/the-history-of-tea/

DeFranzo, S. E. (2011). What's the difference between qualitative and quantitative research? Retrieved on 5 December 2020. Retrieved from https://www.snapsurveys.com/blog/qualitative-vs-quantitative-research/

Durmaz, Y. (2014). The influence of cultural factors on consumer buying behaviour and an application in Turkey. Global Journals Inc. (USA), 14(1), 37-44. 
Durmaz, Y. \& Jablonski, S. (2012). Integrated approach to factors affecting consumers purchase behavior in Poland and an empirical Study. Global Journals Inc. (USA), 12(15), 61-87.

Farooq, U. (2016). Stages of consumer decision making process. Retrieved on 8 December 2020. Retrieved from https://www.businessstudynotes.com/marketing/marketingmanagement/stages-consumer-decision-making-process/

Foong (2019). The boba business: of selfies and bubble tea. Retrieved on 15 October 2020. Retrieved from: https://www.unreservedmedia.com/the-boba-business-of-selfies-andbubble-tea/

Gajjar, N. B. (2013). Factors affecting consumer behavior. International Journal of Research In Humanities and Social Sciences, 1(2), 10-15.

Gbadamosi, A. (2019). A conceptual overview of consumer behavior in the contemporary developing nations. In Handbook of Research on Consumerism and Buying Behavior in Developing Nations by Gbadamosi, Ayantunji, pp. 1-29.

Grimsley, S. (2015). What is consumer buying behaviour?- definition \& type. Retrieved on 15 October 2020. Retrieved from: https://study.com/academy/lesson/what-is-consumerbuying-behavior-definition-types-quiz.html

Hyatt, P. (2017). 7 cultural factors you need to consider when choosing your next export market. Retrived on 10 December. Retrieved from http://www.tradeready.ca/2017/topics/researchdevelopment/5-cultural-factors-needconsider-choosing-next-export-market/

Juneja, P. (2015). Cultural factors affecting consumer behaviour. Retrieved on 2 December 2020. Retrieved from https://www.maneagementstudyguide.com/consumer-decisionmaking-process.htm

Juneja, P. (2015). Personal factors affecting consumer behaviour. Retrieved on 2 December 2020. Retrieved from https://www.managementstudyguide.com/personal-factorsaffecting-consumer-behaviour.htm

Juneja, P. (2015). Psychological factors affecting consumer behaviour. Retrieved on 2 December $2020 . \quad$ Retrieved from https://www.managementstudyguide.com/psychological-factors-affecting-consumerbehaviour.htm

Juneja, P. (2015). Social factors affecting consumer behaviour. Retrieved on 2 December 2020. Retrieved from https://www.managementstudyguide.com/social-factors-affectingconsumer-behaviour.htm

Kotler, P. \& Armstrong, G. (2014). Consumer market. In Principles of Marketing by Kotler, W., et al., pp. 251-296.

Kotler, P. \& Armstrong, G. (2016). Principles of marketing. Sixteenth edition. Pearson Education Limited 2016. Pearson Education limited.

Kotler, P. \& Keller, K.L. (2016). Marketing Management. Pearson Education Limited 2016. Pearson Education limited.

Lautiainen, T. (2015). Factors affecting consumers' buying decision in the selection of a coffee brand. Bachelor Thesis, Saimaa University of Applied Sciences, Lappeenranta

Lee, N. N., Vega, A. T., \& Sardena J. (2015). Factors Affecting Consumer's Buying Behaviour on Selected Milk Tea Stores Towards Obtaining Sustainability. SPUQC Student Journal, 9(2), 123-144. 
Mirzaei, H. \& Ruzdar, M. (2010). The impact of social factors affecting consumer behaviour on selecting characteristics of purchased cars. Journal of Payame Noor University, 111.

New Straits Times. (2019). Youth' now defined as those between 15 and 30. Retrieved on 5 October 2020. Retrieved from https://www.nst.com.my/news/nation/2019/07/501288/youth-now-defined-thosebetween-15-and-30

Nguyen, T. H. \& Gizaw, A. (2014). Factors that influence consumer purchasing decisions of private label food products. Bachelor Thesis. Mälardalens University.

Pillai,V. (2019). Bubble tea 'bubble' may burst soon, says economist. Retrieved on 20 October 2019.

Retrieved from: https://www.freemalaysiatoday.com/category/nation/2019/05/30/bubble-tea-bubblemay-burst-soon-says-economist/

Pratap, A. (2019). Effect of demographic factors on consumer behavior: age, sex, income, and education. Retrieved on 10 December 2020. Retrieved from https://notesmatic.com/2017/07/effect-of-demographic-factors-on-consumerbehavior-age-sex-income-and-education/

Ramya N. \& Ali, S. M. (2016). Factors affecting consumer buying behavior. International Journal of Applied Research 2016, 2(10), 76-80.

Rani, P. (2014). Factors influencing consumer behaviour. International Journal of Current Research and Academic Review, 2(9), 52-61.

Rehman, F. U., Yusoff, R. B., Zabri, S. M., \& Ismail, F. (2017). Determinants of personal factors in influencing the buying behavior of consumers in sales promotion: a case of fashion industry. Emerald Publishing Limited, 18(4), 408-424.

Rojak Daily. (2019). Govt To Start Monitoring Bubble Tea Phenomenon In Malaysia. Retrieved on 2 December 2020. Retrieved from www.rojakdaily.com

Roscoe, J. (1975). Fundamental research statistics for the behavioral sciences. International Series in Decision Process, 2nd Edition, Holt, Rinehart and Winston, Inc., New York.

Sangwai, V. \& Deshmukh, R. (2020). Bubble tea market by base ingredient (black tea, green tea, oolong tea, and white Tea), flavor (original flavor, coffee flavor, fruit flavor, chocolate flavor, and others), and component (flavour, creamer, sweetener, liquid, tapioca pearls, and others)- global. Retrieved on 15 October 2020. Retrieved from: https://www.alliedmarketresearch.com/bubble-tea-market

Sarawak Tourism Board (2021). Sibu: experience nature in the heart of borneo. Retrieved on 5 January 2021. Retrieved from https://sarawaktourism.com/attraction/sibu/

Sekaran, U. \& Bougie, R. (2009) Research methods for business: a skill-building approach, 5th Edition. Wiley Publishers.

Shah, A. (2010). Factors affecting consumer behavior. Retrieved on 10 December 2020. Retrieved from https://productmanagement.buzz/index.php/2010/07/27/factors_affecti/

Solomon, M. (1995). Consumer Behaviour. ( $3^{\text {rd }}$ edition), New Jersey: Prentice Hall

Sarawak Government. (2021). Sarawak population. Retrieved on 3 January 2021. Retrieved from https://www.sarawak.gov.my/web/home/article_view/240/175/

The Asean Post Team. (2019). Southeast Asia's bubble tea craze. Retrieved on 13 October 2020. Retrieved from: https://theaseanpost.com/article/southeast-asias-bubble-teacraze 
Thomas, B. (2010). Sibu city population. Retrieved on 1 November 2020. Retrieved from https://www.citypopulation.de/en/malaysia/admin/sarawak/1315_sibu/

Williams, P. (2014). Emotions and consumer behavior. Journal of Consumer Research, 40(5), 8-11.

Wilson, D. B. (2019). Definition of consumer motivation. Retrieved on 5 November 2020. Retrieved from https://bizfluent.com/about-6572429-definition-consumermotivation.html

Wong, D. J. (2018). The potential future of bubble tea that tealive's festival has accidentally proven. Retrieved on 11 November 2020. Retrieved from https://vulcanpost.com/658923/bubble-tea-coffee-malaysia-trends/

Yakup, D. \& Jablonsk, S. (2012). Integrated approach to factors affecting consumers purchase behavior in Poland and an empirical study. Global Journals Inc. (USA), 12(15), 61-87.

Yim, L.P.R. \& Lee, M.X. (2019). Bubble tea craze on grabFood! Retrieved on 15 November 2020. Retrieved from https://engineering.grab.com/bubble-tea-craze-on-grabfood 